\title{
SMAP LEVEL 4 SURFACE AND ROOT ZONE SOIL MOISTURE
}

\author{
R. Reichle ${ }^{l}$, G. De Lannoy ${ }^{2}$, Q. Liu ${ }^{1}$, J. Ardizzone ${ }^{1}$, J. Kimball ${ }^{3}$, and R. Koster ${ }^{l}$ \\ ${ }^{1}$ Global Modeling and Assimilation Office, NASA/GSFC, Greenbelt, MD, USA \\ ${ }^{2}$ Catholic University of Leuven, Leuven, Belgium \\ ${ }^{3}$ University of Montana, Missoula, MT, USA
}

\begin{abstract}
The SMAP Level 4 soil moisture (L4_SM) product provides global estimates of surface and root zone soil moisture, along with other land surface variables and their error estimates. These estimates are obtained through assimilation of SMAP brightness temperature observations into the Goddard Earth Observing System (GEOS-5) land surface model. The L4_SM product is provided at $9 \mathrm{~km}$ spatial and 3-hourly temporal resolution and with about 2.5 day latency. The soil moisture and temperature estimates in the L4_SM product are validated against in situ observations. The L4_SM product meets the required target uncertainty of 0.04 $\mathrm{m}^{3} \mathrm{~m}^{-3}$, measured in terms of unbiased root-mean-squareerror, for both surface and root zone soil moisture.
\end{abstract}

Index Terms - Soil moisture, data assimilation, SMAP

\section{INTRODUCTION}

The NASA Soil Moisture Active and Passive (SMAP) mission [2] has been providing L-band $(1.4 \mathrm{GHz})$ passive microwave brightness temperature $(\mathrm{Tb})$ observations since April 2015. These observations are sensitive to surface (0-5 $\mathrm{cm})$ soil moisture. Several of the key applications targeted by SMAP, however, require knowledge of deeper-layer, "root zone" $(0-100 \mathrm{~cm})$ soil moisture, which is not directly measured by SMAP. The NASA Global Modeling and Assimilation Office (GMAO) contributes to SMAP by providing Level 4 data, including the Level 4 Surface and Root Zone Soil Moisture (L4_SM) product, which is based on the assimilation of SMAP $\mathrm{Tb}$ observations in the ensemble-based NASA GEOS-5 land surface data assimilation system [5].

\section{L4_SM PRODUCT AND ALGORITHM}

The L4_SM product offers global data every three hours at 9 $\mathrm{km}$ resolution, thereby interpolating and extrapolating the coarser-scale $(\sim 40 \mathrm{~km})$ SMAP observations in time and in space (both horizontally and vertically). Since 31 October 2015, beta-version L4_SM data have been available to the public from the National Snow and Ice Data Center (NSIDC; http://nsidc.org/data/smap) for the period 31 March 2015 to near present, with a mean latency of $\sim 2.5$ days.

The land surface model component of the assimilation system, the NASA GEOS-5 Catchment land surface model [3], is driven with observations-based surface meteorological forcing data, including precipitation [4], which is the most important driver for soil moisture. The model also encapsulates knowledge of key land surface processes, including the vertical transfer of soil moisture between the surface and root zone reservoirs. The radiative transfer model to simulate L-band brightness temperatures was calibrated using observations from the Soil Moisture and Ocean Salinity mission [1]. The horizontally distributed ensemble Kalman filter update step considers the respective uncertainties of the model estimates and the observations.

\section{SOIL MOISTURE ANALYSIS}

Figure 1 illustrates, for 29 May 2015, 0z, the soil moisture and temperature analysis that lies at the heart of the L4_SM algorithm. The panels only show a part of North America (the continental United States and portions of Mexico and Canada) to reveal the details of the global analysis. Figure 1a depicts the map of $\mathrm{H}$-pol brightness temperature observation-minus-forecast (O-F) residuals, which typically range between $-15 \mathrm{~K}$ and $15 \mathrm{~K}$. V-pol data exhibit similar features (Figure 1b). At the analysis time in question, brightness temperature observations were available from two ascending swaths, one crossing the eastern portion and another crossing the western portion of North America. Observations were not assimilated everywhere. For example, the quality control steps in the L4_SM processing exclude brightness temperature observations in the vicinity of open water surfaces or where model temperatures indicate surface conditions near or below freezing, for example, in the Rocky Mountains.

Note that while the O-F residuals are posted on a $9 \mathrm{~km}$ grid, the assimilated L1C_TB brightness temperature observations and thus the O-F residuals, are of much coarser resolution $(\sim 40 \mathrm{~km})$. In contrast, the increments and the 
L4 SM product are at the $9 \mathrm{~km}$ resolution of the land surface model. One key feature of the L4_SM analysis is the downscaling of the SMAP radiometer data to the $9 \mathrm{~km}$ model resolution based on the modeled error characteristics, which vary dynamically and spatially.

Figures 1c, e, and $\mathrm{g}$ show the resulting analysis increments in surface soil moisture, root zone soil moisture, and surface soil temperature, respectively. Areas where the observed brightness temperature is warmer than the model forecast result in negative increments in soil moisture and positive increments in soil temperature. Increments in surface soil moisture typically range from $-0.03 \mathrm{~m}^{3} \mathrm{~m}^{-3}$ to $0.03 \mathrm{~m}^{3} \mathrm{~m}^{-3}$. Increments in root zone soil moisture are generally smaller and mostly range between $-0.01 \mathrm{~m}^{3} \mathrm{~m}^{-3}$ and $0.01 \mathrm{~m}^{3} \mathrm{~m}^{-3}$, reflecting the fact that the brightness temperature observations are directly sensitive only to the soil moisture and temperature in a surface layer of approximately $5 \mathrm{~cm}$ thickness. Root zone soil moisture increments rely on the error cross correlations between the modeled brightness temperatures and root zone soil moisture that evolve dynamically with the model ensemble.

The analysis increments are generally smooth and cover an area that is slightly larger than the coverage of the O-F residuals, owing to the spatially distributed (threedimensional) ensemble Kalman filter used in the L4_SM analysis. Finally, Figures 1d, f, and h show the resulting analysis fields for surface soil moisture, root zone soil moisture, and surface soil temperature, respectively. The analysis fields are computed by adding the analysis increments of Figures 1c, e, and g to the model forecast (not shown). Figures $1 \mathrm{~d}, \mathrm{f}$, and $\mathrm{h}$ illustrate that the analysis increments blend seamlessly into the model forecast fields, and that the geometrical features of the satellite swaths of assimilated observations cannot be discerned in the final analysis.

\section{IN SITU VALIDATION}

The quality of the L4_SM product is assessed against in situ measurements from watersheds with locally dense sensor networks and continental-scale sparse networks [5]. These comparisons indicate that the current beta-version of the L4_SM data product meets the mission accuracy requirement, which is formulated in terms of the ubRMSE: the RMSE after removal of the long-term mean difference. For the period 31 March to 25 October 2015, the overall ubRMSE of the 3-hourly L4_SM surface soil moisture at the $9 \mathrm{~km}$ scale is $0.037 \mathrm{~m}^{3} / \mathrm{m}^{3}$. The corresponding ubRMSE for L4_SM root zone soil moisture is $0.024 \mathrm{~m}^{3} / \mathrm{m}^{3}$. Both of these metrics are well below the $0.04 \mathrm{~m}^{3} / \mathrm{m}^{3}$ ubRMSE requirement.

\section{REFERENCES}

[1] G. J. M. De Lannoy, R. H. Reichle, and V. R. N. Pauwels, "Global Calibration of the GEOS-5 L-band Microwave Radiative Transfer Model over Nonfrozen Land Using SMOS Observations," Journal of Hydrometeorology, 14, 765-785, doi:10.1175/JHM-D12-092.1, 2013.

[2] D. Entekhabi, and Coauthors, "The Soil Moisture Active and Passive (SMAP) Mission," Proceedings of the IEEE, 98, 704-716, doi:10.1109/JPROC.2010.2043918, 2010.

[3] R. D. Koster, M. J. Suarez, A. Ducharne, M. Stieglitz, and P. Kumar, "A catchment-based approach to modeling land surface processes in a general circulation model, 1: Model structure," $J$. Geophys. Res. 105, 24809-24822, 2000.

[4] R. H. Reichle, and Q. Liu, "Observation-Corrected Precipitation Estimates in GEOS-5," NASA Technical Report Series on Global Modeling and Data Assimilation, NASA/TM2014-104606, Vol. 35, National Aeronautics and Space Administration, Goddard Space Flight Center, Greenbelt, Maryland, USA, 18pp, 2014. Available at: http://gmao.gsfc.nasa.gov/pubs/.

[5] R. H. Reichle, and Coauthors, "Soil Moisture Active Passive (SMAP) Project Assessment Report for the Beta-Release L4_SM Data Product," NASA Technical Report Series on Global Modeling and Data Assimilation, NASA/TM-2015-104606, Vol. 40, National Aeronautics and Space Administration, Goddard Space Flight Center, Greenbelt, Maryland, USA, 63pp, 2015. Available at: http://gmao.gsfc.nasa.gov/pubs/. 


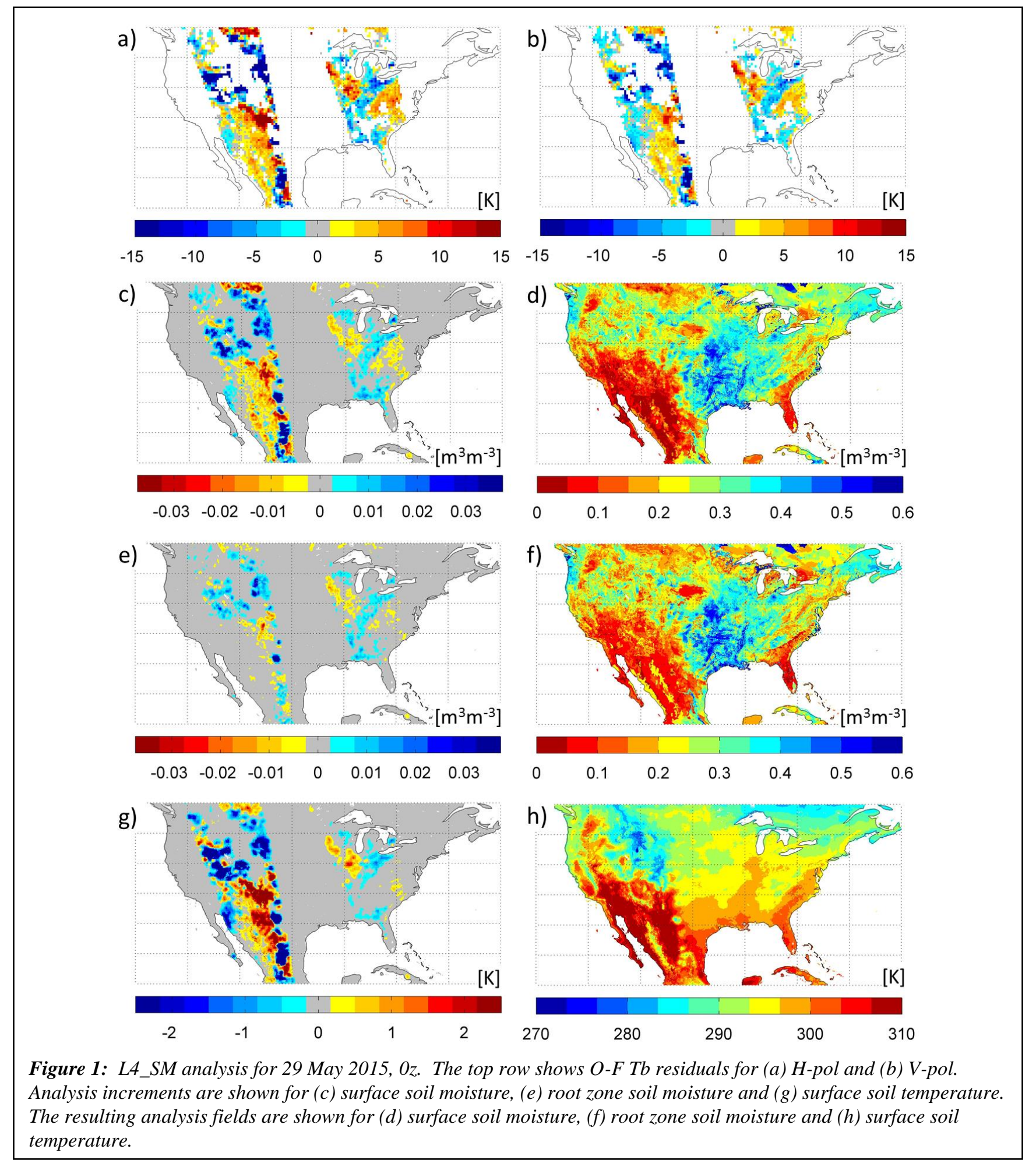

